\title{
Hepatoprotective Activity of Hedyotis corymbosa (Linn.) Lam. Extract Against Anti-Tubercular Drug Induced Hepatic Damage in Sprague-Dawley Rats
}

\author{
Shah Marzia Mahjabin Lina', Imran Ashab², M Salahuddin Bhuiya ${ }^{2}$ \\ and Masum Shahriar ${ }^{2}$ \\ ${ }^{1}$ Department of Pharmacy, Stamford University Bangladesh, Dhaka-1217, Bangladesh \\ ${ }^{2}$ Department of Pharmacy, Jahangirnagar University, Savar, Dhaka-1342, Bangladesh
}

(Received: 28 March, 2018; Accepted: 1 June, 2018; Published: 31 July, 2018)

\begin{abstract}
The aim of this study was to investigate the protective actions of hydroalcoholic extract of Hedyotis corymbosa against hepatotoxicity caused by different combinations of anti-tubercular drugs. Antitubercular drugs isoniazid and rifampicin were used to make the elevated level of ALT, AST, ALP and bilirubin as well as decreased level of albumin and total protein. Hepatoprotective activity of the plant was indicated when it causes the decrease of these marker enzymes and elevated level of albumin and total protein. H. corymbosa prevented liver damage caused by anti-tubercular drugs and also from histopathological changes. It can be concluded from the above experiment that hydroalcoholic extract of $H$. corymbosa showed significant hepatoprotective activity against antitubercular drugs.
\end{abstract}

Key words: Isoniazid, rifampicin, hepatotoxicity, anti-tubercular, Hedyotis corymbosa.

\section{Introduction}

Tuberculosis (TB) continues to be a health problem. Short course combination chemotherapy of isoniazid (INH), rifampin (RMP) and pyrazinamide (PZA) is highly effective in the management of TB. Rifampicin has bactericidal activity against $M$. tuberculosis by inhibiting bacterial DNA dependent RNA polymerase (Houston and Fanning, 1994). Isoniazid is a prodrug activated by bacterial catalaseperoxidase (KatG) and kills actively growing tubercle bacilli by inhibiting the biosynthesis of mycolic acids which are major components of cell wall of $M$. tuberculosis (Timmins and Deretic, 2006). The another prodrug pyrazinamid is activated by bacterial pyrazinamidinase which is only active in acidic conditions (pH: 5.5). The active metabolite of pyrazinamid is pyrazinoic acid that inhibits fatty acid synthesis in M. tuberculosis (Zimhony et al., 2000).
This drug is used in the initial two months of treatment to reduce the duration of therapy and is not used alone. Several adverse reactions of antitubercular drugs are reported. The best known toxic drug effect is hepatotoxicity. The frequency and severity of hepatotoxicity is increased when these drugs are used in combination (Petri, 2001; Zimhony et al., 2000).

Hedyotis corymbosa (L.) Lam. syn. Oldenlandia corymbosa (L.) Lam. (Rubiaceae) is a weedy herb, widely distributed throughout India. It is commonly known as 'Parppatakapullu' in traditional medicine of Kerala. H. corymbosa is extensively used in modern Chinese practice for the treatment of viral infections, cancer, syndromes involving "toxic heat", acne, boils, skin ailments, appendicitis, hepatitis, eye diseases and bleeding. They call it 'Peh-Hue-JuwaChi-Cao' (Lin et al., 2004). The plant is used for

Corresponding Aurthor: Shah Marzia Mahjabin Lina. Tel: +880 02711350 E-mail address: lina_pharmju@yahoo.com 
treating venomous bites. It has anthelmintic, diuretic, depurative, diaphoretic, expectorant, digestive and stomachic properties (Kirtikar and Basu, 1994). It is given in jaundice and other diseases of the liver, heat eruptions, vitiated conditions of pitta, hyperdypsia, giddiness, dyspepsia, flatulence, colic, constipation, helminthiasis, leprosy, skin diseases, cough, bronchitis, necrosis, nervous depression caused by deranged bile and hepatopathy (Warrier et al., 1995). Recently there have been many studies on traditional medicines, attempting to develop new drugs for hepatitis from them. So far, there has been several research reported on hepatoprotective effect of $H$. corymbosa (L.) against D-galactosamine (Gupta et al., 2012), carbon tetrachloride (Wang et al., 2011) and paracetamol (Sultana et al., 2010) induced liver damage in rats. However, there are no reports on hepatoprotetive effect of $H$. corymbosa (L.) against anti-tubercular drug induced hepatic damage. A search for an alternative drug useful for the prophylactic treatment of hepatotoxicity induced by anti-tubercular drugs still remains important. Efforts to explore hepatoprotective effect of any natural product thus carry a great clinical significance. Therefore, the present study was undertaken for the first time for the hepatoprotective activity of $H$. corymbosa (L.) extract against antitubercular drug induced hepatotoxicity in rats.

\section{Materials and Methods}

Plant material: Whole plants of $H$. corymbosa was collected from Jahangirnagar University Campus, Savar, Dhaka-1342.

Preparation of extract: The whole plants of $H$. corymbosa were washed thoroughly in tap water, shade dried and powdered. The powder (100 g) was successively extracted with $1000 \mathrm{ml}$ of ethanol overnight with constant stirring. The filtrate was then concentrated and the solvent was evaporated under reduced pressure in a rotary evaporator. The yield of the extract was found to be $0.42 \%(\mathrm{w} / \mathrm{v})$. This crude extract was referred to as HC. For administration, the crude extract was suspended in distilled water to make required concentrations.
Experimental animals: Adult male rats (Rattus novergicus: Sprague-Dawley strain) were collected from central animal house of the Department of Pharmacy, Jahangirnagar University, Savar, Dhaka1342. The animals were randomized and separated into normal and experimental groups of body weight ranging from 170 to $230 \mathrm{~g}$.

Experiment design: Animals were divided into following four groups:

Group I: Normal control $(n=6$, the animals were given normal saline only for 28 days)

Group II: Standard ( $\mathrm{n}=6$, the animals were given Silymarin only for 28 days)

Group III: Hepatotoxic control $(\mathrm{n}=6$, the animals were given INH+RIF for 28 days)

Group IV: Treatment group ( $\mathrm{n}=6$, the animals were given INH+RIF+HC for 28 days)

Rats were treated as per the treatment protocol. Body weights of these rats were monitored sequentially in control and experimental animals for a period of 28 days.

Dose and route of administration: Isoniazid and rifampicin $(50 \mathrm{mg} / \mathrm{kg}$ body weight) solutions were prepared separately in sterile distilled water. Rats were treated with isoniazid, co-administered with rifampicin for 28 days by oral route (Hewawasam et al., 2003). For hepatotoxic model, 50 $\mathrm{mg} / \mathrm{kg}$ per day of INH and RIF each was used in the study (Jiang et al., 2004). For the hepatoprotective model, $500 \mathrm{mg} / \mathrm{kg}$ per day of freshly prepared $H$. corymbosa homogenate along with INH+RIF solution was administered orally and Silymarin was administered at a dose of $50 \mathrm{mg} / \mathrm{kg}$.

Preparation of the samples for biochemical studies: From the post vena cava of the animal, blood samples were collected and immediately blood was transferred to the tubes having heparin. Blood samples were centrifuged for 10 minutes at $3000 \mathrm{rpm}$ to separate serum for biochemical analysis. The liver was dissected out for histopathological examinations.

Assessment of liver functions: Biochemical parameters such as, serum alanine aminotransferase (ALT), serum aspartate aminotransferase (AST), 
serum bilirubin (SB), serum alkaline phosphatase (ALP) (Malloy and Evelyn, 1937; Reitman and Frankel, 1957), total protein (TP) (Reinhold, 1953; Lowry et al., 1951) and albumin (Lowry et al., 1951) were determined by Humalyzer-3500 auto-analyzer using kits manufactured by HUMAN GmbH, Germany in Pharmacology Lab at Jahangirnagr University, Savar, Dhaka, Bangladesh.

Histopathological studies: The liver specimens obtained from the control and treated groups of animals were fixed in $10 \%$ buffered formalin for 24 h. The formalin-fixed liver samples were stained with haematoxylin-eosin for photomicroscopic observations of the liver histological architecture (Kalyani et al., 2010).

Estimation of in vitro antioxidant activity: The method of Ottolenghi (1959) was used to determine the thiobarbituric acid (TBA) values of the samples. Two milliliters of $20 \%$ trichloroacetic acid and $2 \mathrm{ml}$ of thiobarbituric acid aqueous solution were added to $1 \mathrm{ml}$ of sample solution prepared as in ferric thiocyanate (FTC) procedure and incubated in a similar manner. The mixture was placed in boiling water bath for $10 \mathrm{~min}$. After cooling, it was centrifuged at $3000 \mathrm{rpm}$ for $20 \mathrm{~min}$ and the absorbance of the supernatant was measured at 532 nm. Antioxidant activity was based on the absorbance on the final day. The inhibition of lipid peroxidation in percentage was calculated by the following equation:

$$
\text { Percent inhibition }=1-\frac{\mathrm{A}_{1}}{\mathrm{~A}_{0}}
$$

Where, $A_{0}$ is the absorbance of control and $A_{1}$ is the absorbance of sample (Duh et al., 1999).

Statistical analysis: All the grouped data were statistically evaluated with SPSS (Chicago, IL) version 16.5 software. All the results were expressed as mean \pm SEM (Standard error of mean) values for six animals in each group. Means were compared by independent sample t-test. Probability $(p)$ value of 0.05 or less $(\mathrm{p}<0.05)$ was considered as significant.

\section{Results and Discussion}

Administration of isoniazid and rifampicin (50 $\mathrm{mg} / \mathrm{kg}$, p.o.) induced a marked increase in the serum hepatic levels of AST, ALT, ALP, SB and induced a marked decrease in total protein and albumin level as compared to normal controls indicating liver damage. Pre-treatment of the rats with $\mathrm{HC}(500 \mathrm{mg} / \mathrm{kg})$ prior to isoniazid and rifampicin administration caused a significant reduction in the values of AST, ALT, ALP and SB but increase in total proein and albumin level. Same result was observed in case of standard drug Silymarin (Table 1).

The hepatoprotective effect of $H$. corymbosa was confirmed by histopathological examination of the liver tissue of control and treated animals. The histological architecture of isoniazid and rifampicin treated liver sections showed massive hepatic necrosis with dilated blood vessels in comparison with normal control. However, administration of $H$. corymbosa $(500 \mathrm{mg} / \mathrm{kg})$ causes blood vessels dilation and proliferation of bile canaliculi. It also normalize the defects in the histological architecture almost to the level of the control groups, showing its potent hepatoprotective effects of the plant extract and Silymarin (Figures 1-4). The antioxidant activity exhibited by $H$. corymbosa in TBA methods (in vitro) is represented in table 3 .

Tuberculosis is a leading public health problem worldwide, particularly in developing countries. About one third of world's population has latent tuberculosis and approximately 9 million cases of active tuberculosis emerge annually resulting in 2-3 million deaths (Adhvaryu et al., 2007). Out of 1.86 billion people estimated to be infected with the tuberculosis bacillus, an estimated 1.3 billion infected people are living in developing countries, such as India and China (Santhosh et al., 2006). In view of the seriousness of the problem World Health Organization (WHO) declared it to be a global emergency in 1993. Active tuberculosis will kill about two out of every three people if untreated. 
Table 1. Effects of alcoholic extract of $H$. corymbosa on rat serum parameters after INH + RIF administration.

\begin{tabular}{llll}
\hline Group & ALT (IU/L) & AST (IU/L) & ALP (KA Units/100 ml) \\
\hline Control & $17.33 \pm 3.39$ & $23.83 \pm 4.31$ & $144.50 \pm 5.28$ \\
Silymarin & $21.23 \pm 3.12^{\mathrm{a}}$ & $31.152 \pm 4.11^{\mathrm{a}}$ & $151.25 \pm 6.78^{\mathrm{a}}$ \\
INH+RIF & $56.67 \pm 3.98$ & $78.00 \pm 5.55$ & $177.83 \pm 17.07$ \\
INH+RIF+HC & $33.50 \pm 7.87^{\mathrm{a}}$ & $52.33 \pm 9.71^{\mathrm{a}}$ & $163.17 \pm 11.87$ \\
\hline
\end{tabular}

Results are represented as mean $\pm \operatorname{SEM}(n=6)$. ${ }^{\mathrm{a}} \mathrm{p} \leq 0.001$, compared to INH+RIF

ALT- Alanine transaminase, AST- Aspartate aminotransferase, ALP- alkaline phosphatase.

Table 2. The levels of albumin, total protein and total bilirubin after the treatment of rats with antitubercular drugs and $\mathrm{H}$. corymbosa.

\begin{tabular}{llll}
\hline Group & Bilirubin $(\mathrm{mg} / \mathrm{dl})$ & Total Protein $(\mathrm{mg} / \mathrm{dl})$ & Albumin $(\mathrm{mg} / \mathrm{dl})$ \\
\hline Control & $0.33 \pm 0.15$ & $6.26 \pm 0.29$ & $4.35 \pm 0.44$ \\
Silymarin & $0.31 \pm 0.04^{\mathrm{a}}$ & $6.08 \pm 0.12^{\mathrm{a}}$ & $4.32 \pm 0.09^{\mathrm{a}}$ \\
INH+RIF & $1.22 \pm 0.16$ & $4.85 \pm 0.62$ & $3.68 \pm 0.31$ \\
INH+RIF+HC & $0.55 \pm 0.19^{\mathrm{a}}$ & $5.61 \pm 0.41^{\mathrm{b}}$ & $4.09 \pm 0.12^{\mathrm{b}}$ \\
\hline
\end{tabular}

Results are represented as mean $\pm \operatorname{SEM}(n=6) .{ }^{a} \mathrm{p} \leq 0.001$, compared to $\mathrm{I}+\mathrm{R},{ }^{\mathrm{b}} \mathrm{p} \leq 0.05$, compared to INH+RIF
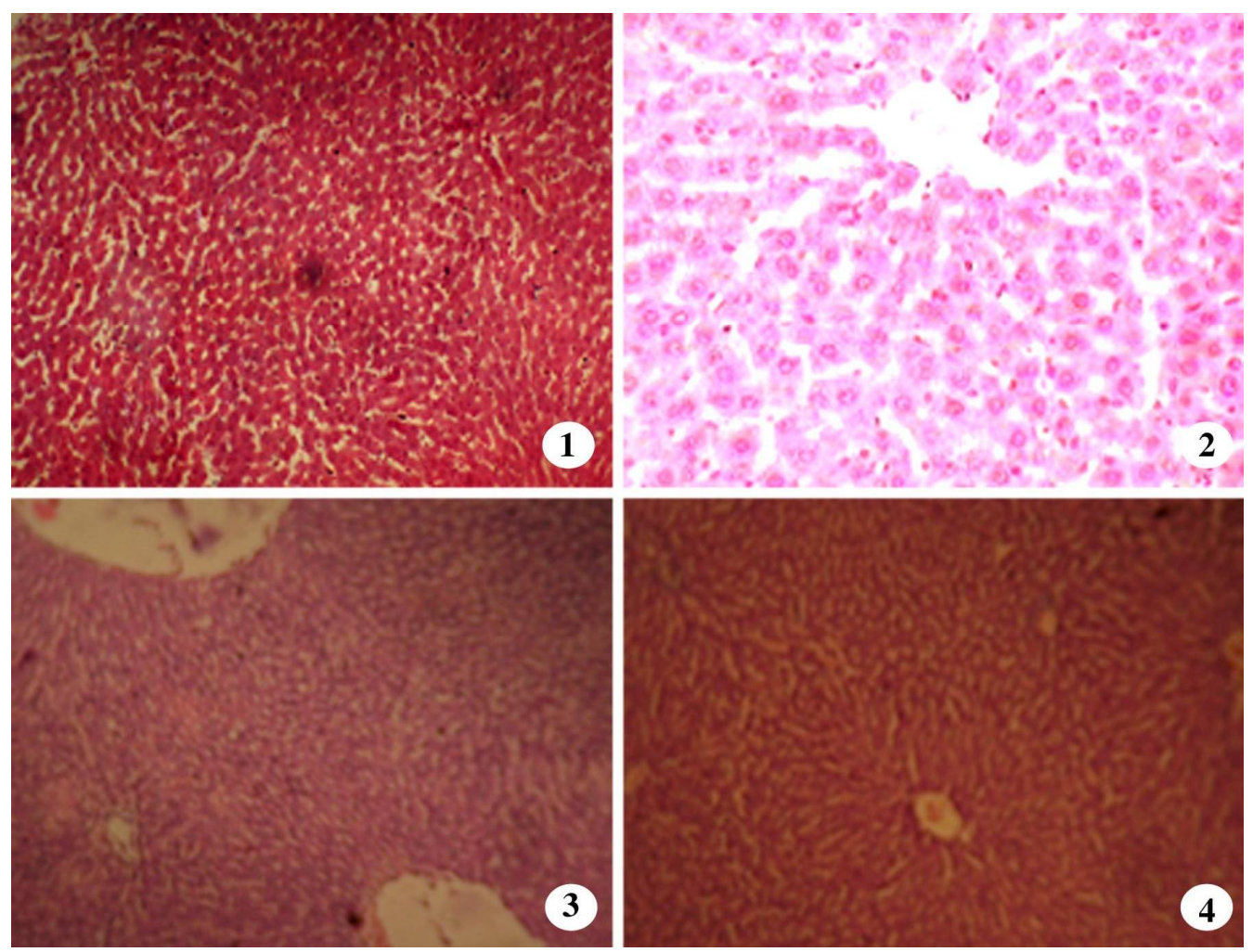

Figures 1-4. 1.Section of control rat liver, showing normal architecture of hepatic cell. 2. Section of Silymarin rat liver, showing almost normal architecture of hepatic cell. 3. Section of INH-RIF treated rat liver, showing massive hepatic necrosis with dialated blood vessels. 4. Section of $H$. corymbosa. $(500 \mathrm{mg} / \mathrm{kg})$ treated rat liver, showing marked improvement over INH + RIF group 
Table 3. $\mathrm{IC}_{50}$ values of the plant extract and standard.

\begin{tabular}{ll}
\hline Sample/Standard & $\mathrm{IC}_{50}(\mu \mathrm{g} / \mathrm{ml})$ \\
\hline H. corymbosa & 361.63 \\
BHT & 53.36 \\
\hline
\end{tabular}

Drug-induced hepatotoxicity is a potentially serious adverse effect of the currently used antitubercular chemotherapeutic regimens containing INH, RMP and PZA. All these drugs are potentially hepatotoxic independently and when given in combination their toxic effects are enhanced in a synergistic manner. The conversion of monoacetyl hydrazine, a metabolite of INH to a toxic metabolite via cytochrome $\mathrm{P}_{450}$ leads to hepatotoxicity. RMPinduces cytochrome P450 enzyme causing an increased production of toxic metabolites from acetyl hydrazine (AcHz). RMP also increase the metabolism of INH to isonicotinic acid and hydrazine, both of which are hepatotoxic. The plasma half life of $\mathrm{AcHz}$ (metabolite of INH) is shortened by RMP and $\mathrm{AcHz}$ is quickly converted to its active metabolite by increasing the oxidative elimination rate of $\mathrm{AcHz}$, which is related to the higher incidence of liver necrosis caused by INH and RMP in combination (Hussain et al., 2003).

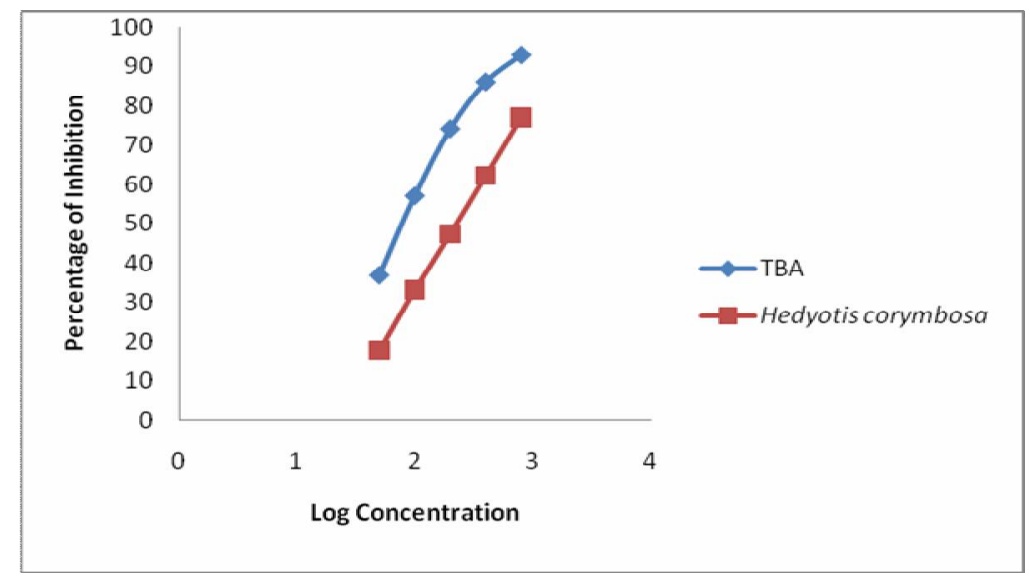

Figure 5. Lipid peroxidation inhibition capacity of Hedyotis corymbosa and BHT

Rats have been used successfully to investigate INH and RIF-induced hepatotoxicity models (Tasduq et al., 2005; Pal et al., 2006; Victorrajmohan et al., 2005; Rana et al., 2006). Therefore, we selected rats to study the hepatotoxic effect of antitubercular drugs and hepatoprotective action of $H$. corymbosa. The doses of the drugs used (INH: $50 \mathrm{mg} / \mathrm{kg}$ and RIF: 50 $\mathrm{mg} / \mathrm{kg}$ ) are very high compared to those used in the treatment of tuberculosis in human subjects. However, higher doses of drugs are required in animal models to produce hepatotoxicity, because rats metabolize the drugs at a faster rate and the duration of treatment is much shorter compared to the treatment of tuberculosis in humans. Biochemical tests have been done to follow hepatocellular integrity and liver injury. In this study, the injection of INH and RIF caused a significant elevation in the activities of ALT, AST and ALP. Serum total bilirubin was also increased two fold, indicating membrane damage in the liver (Table 2). Decrease in albumin and total protein levels proved that administration of drugs caused impairment of liver function to synthesize albumin (Table 2).

Pre-treatment of the rats with $H$. corymbosa extract at $500 \mathrm{mg} / \mathrm{kg}$, resulted in a significant protection of INH+RIF induced elevation of serum marker enzymes. H. corymbosa appears to be effective in reducing the injurious effect of INH+RIF 
observed in the present study. This was an indication of stabilization of plasma membrane, as well as repairment of hepatic tissue damage, caused by INH+RIF. The results are in agreement with the commonly accepted view that serum level of transaminase returns to normal with healing of hepatic parenchyma and the regeneration of hepatocytes (Thabrew et al., 1987). Further, the stimulation of hepatic regeneration was known to make the liver more resistant to damage by toxins (Lesch et al., 1970). The hepatoprotective effect of $H$. corymbosa was further confirmed by histopathological examination of the liver. The histological observation basically supported the results from the serum assays as $H$. corymbosa administration reversed to a large extent of hepatic lesions produced by INH+RIF.

From the aerial parts of $H$. corymbosa nine iridoid glycoside derivatives were isolated (Otsuka $e t$ al., 1991). The iridoid glycosides isolated from Picrorrhiza kurroa showed marked protective action on liver against CCl4-intoxicated rats by enhancing the choleretic activity and also reduced the levels of SGOT and SGPT (Handa et al., 1986). H. corymbosa has also been reported to contain oleanolic acid, ursolic acid and $\gamma$-sitosterol (Khastgir et al., 1960). Ursolic acid exhibited potent hepatoprotective effects (Shukla et al., 1992a,b; Liu, 1995). Oleanolic acid has been reported to increase the antioxidant components in the liver, such as glucuronosyl transferase towards acetaminophen in mice. It also increased/maintained the hepatic glutathione, which plays an important role in protecting acetaminopheninduced liver injury (Zhang and Li, 1992; Liu, 1995). Inhibition of lipid peroxidation by oleanolic acid is also proposed to play a role in preventing $\mathrm{CCl}_{4}$ and dgalactosamine plus endotoxin-induced liver injury (Balanehru and Nagarajan, 1991; Zhang and Li, 1992; Liu et al., 1993). Preventing liver lesions from progressing to fibrosis and cirrhosis, and repairing parenchymal cell damage by stimulating liver regeneration are important mechanisms for hepatoprotection. Perhaps the triterpenoids and iridoid glycosides present in $H$. corymbosa are responsible for the marked hepatoprotective effects, observed in the present study.

In TBA method, formation of malonaldehyde is the basis for evaluating the extent of lipid peroxidation. At low $\mathrm{pH}$ and high temperature $\left(100^{\circ} \mathrm{C}\right)$ malonaldehyde binds TBA to form a red complex that can be measured at $532 \mathrm{~nm}$. The increase of the amount of red pigment formed correlates with the oxidative rancidity of the lipid. Most of the hepatotoxic chemicals including isoniazid and rifampicin damage liver mainly by inducing lipid peroxidation directly or indirectly. In higher animals, lipid peroxidation was known to cause destabilization and disintegration of the cell membrane, leading to liver injury, arteriosclerosis and kidney damage (Rael et al., 2004). Peroxy radicals are important agents that mediate lipid peroxidation thereby damaging cell membrane. The $\mathrm{IC}_{50}$ values of the plant extract and standard are presented in table $3 . \%$ inhibition of lipid peroxidation was found to rise with increasing concentration of plant extract (Figure 4).

In conclusion, the findings of this study demonstrates that $H$. corymbosa has potent hepatoprotective activity upon INH+RIF-induced hepatic damage in rats and antilipid peroxidative activity. The present study thus justifies the traditional use of $H$. corymbosa in the treatment of liver diseases. This study also points out that $H$. corymbosa warrants detailed investigation for developing promising hepatoprotective agents.

\section{Acknowladgement}

The authors are extremely thankful to Prof. Mohammad Sahbuddin Kabir Choudhuri of Department of Pharmacy, Jahangirnagar University.

\section{References}

Adhvaryu, M.R., Reddy, N. and Parabia M.H. 2007. Effects of four indian medicinal herbs on izoniasidand pyrazinamide-induced hepatic injury and immunosuppression in guinea pigs. Word $J$. Gastroenterol. 13, 3199-3205. 
Balanehru, S. and Nagarajan, B. 1991. Protective effect of oleanolic acid and ursolic acid against lipid peroxidation. Biochemistry Inter. 24, 981-990.

Gupta, R.K., Singh, R.K., Swain, S.R., Hussain, T. and Rao C.V. 2012. Anti-hepatotoxic potential of Hedyotis corymbosa against D-galactosamine-induced hepatopathy in experimental rodents. Asian Pacific J. Tropical Biomedicine. S1542-S1547

Handa, S.S., Sharma, A. and Chakraborti, K.K. 1986. Natural products and plants as liver protecting drugs. Fitoterapia 57, 307-349.

Haryanti, S., Junedi, S. and Meiyanto, E. 2009. Ethanolic extract of Hedyotis corymbosa L. increases cytotoxic activity of Doxorubicin on MCF-7 breast cancer cell. Indonesian J. Biotechnology. 14, 1146-1154.

Hewawasam, R.P., Jayatilaka, K.A., Pathirana, C. and Mudduwa, L.K. 2003. Protective effect of Asteracantha longifolia extract in mouse liver injury induced by carbon tetrachloride and paracetamol. $J$. Pharma. Pharmacol. 55, 1413-1418.

Hussain, Z., Kar, P. and Hussain, S.A. 2003. Antituberculosis drug-induced hepatic: risk factor, prevention and management. Indian J. Exp. Biol. 41, 226- 1232.

Jiang, Y.U.E., Peng, R., Yang, J., Kong, R. and Liu, J.. 2004. CYP2E1 mediated isoniazid-induced hepatotoxicity in rats. Acta Pharmacol. Sin. 25, 699-704.

Kalyani, M., Rathi, M.A., Thirumoorthi, L., Meenakshi, P., Kumar, G.D., Sunitha, M. and Gopalakrishnan, V.K. 2010. Asteracantha longifolia inhibits perchloroethylene - induced hepatic damage in rat. J. Pharma. Res. 3, 1535-1537.

Khastgir, H.N., Sengupta, S.K. and Sengupta, P. 1960. Note on the constituents of the Indian medicinal plant Oldenlandia corymbosa Linn. J. American Pharma. Association 49, 562-563.

Kirtikar, K.R. and Basu, B.D. 1994. Indian Medicinal Plants, vol. 2. Bishen Singh, Mahendrapal Singh, Dehradun. p.1263.

Lesch, R., Reutter, W., Keppler, D. and Decker, K. 1970. Liver restitution after acute galactosamine hepatitis: autoradiographic and biochemical studies in rats. Experimental Molecular Pathology 12, 58-69.

Lin, C.C., Ng, L.T. and Yang, J.J. 2004. Antioxidant activity of extracts of "Peh- Hue-Juwa-Chi-Cao" in a cell free system. American J. Chinese Med. 32, 339349.
Liu, J. 1995. Pharmacology of oleanolic acid and ursolic acid. J. Ethnopharmacol. 49, 57-68.

Liu, Y.P., Liu, J. and Klaassen, C.D. 1993. The protection of oleanolic acid on d-galactosamine/endotoxininduced hepatotoxicity. Toxicologist. 13, 720-722.

Lowry, O.H., Rosebrough, N.J. and Farr, A.L. 1951. Protein measurement with the Folin phenol reagent. $J$. Biol Chem. 193, 265-75.

Malloy, H.T. and Evelyn, K.A. 1937. The determination of bilirubin with the photometric colorimeter. J. Biol. Chem.. 119, 481-490.

Otsuka, H., Yoshimura, K., Yamasak,i K. and Cantoria, M.C. 1991. Isolation of acyl iridoid glycosides from a Philippine medicinal plant Oldenlandia corymbosa. Chemical and Pharmaceutical Bulletin 39, 2049-2052.

Pal, R., Vaiphei, K., Sikande,r A., Singh, K. and Rana, S.V. 2006. Effect of garlic on isoniazid and rifampicininduced hepatic injury in rats. World Gastroenterol. 12, 636-639.

Rael, L.T., Thomas, G.W., Craun, M.L., Curtis, C.G., Baror. R. and Bar-Or. D. 2004. Lipid peroxidation and the thiobarbituric acid assay: standardization of the assay when using saturated and unsaturated fatty acids. $J$. Biochem. Mol. Biol. 37, 749-752.

Rana, S.V., Attri, S., Vaiphei, K., Pal, R., Attr,i A. and Singh, K. 2006. Role of $\mathrm{N}$-acetylcysteine in rifampicin-induced hepatic injury of young rats. World Gastroenterol. 12, 287-291.

Reitman, S. and Frankel, S., 1957. Determination of serum glutamate oxaloacetate and glutamic pyruvic acid transaminases. Amer. J. Clinical Path. 28, 56-66.

Santhosh, S., Sini, T.K., Anandan, R. and Mathew, P.T. 2006. Effect of chitosan supplementation on antitubercular drugs-induced hepatotoxicity in rats. Toxicology. 219, 53-59.

Shukla, B., Visen, P.K.S., Patnaik, G.K. and Dhawan, B.N. 1992B The hepatoprotective principle of Picrorrhiza kurroa. Planta Med. 57, 29-33.

Shukla, B., Visen, S., Patnaik, G.K., Tripathi, S.C., Srimal, R.C., Day, S. and Dobhal, P.C. 1992A Hepatoprotective activity in the rat of ursolic acid isolated from Eucalyptus hybrid. Phytotherapy Res. 6, 74-79.

Sultana, T., Rashid, M.A., Ali, M.A. and Mahmood, S.F. 2010. Hepatoprotective and antibacterial activity of ursolic acid extracted from Hedyotis corymbosa L. Bangladesh J. Sci. Ind. Res. 45, 27-34. 
Tasduq, S.A., Peerzada, K., Kou,l S., Bhat, R. and Johri, R.K. 2005. Biochemical manifestations of antituberculosis drug induced hepatotoxicity and the effect of silymarin. Hepatol. Res. 31, 132-135.

Thabrew, M.I., Joice, P.D.T.M. and Rajatissa, W.A. 1987. Comparative study of the efficacy of Pavetta indica and Osbeckia octandra in the treatment of liver function. Planta Medica. 53, 239-241.

Victorrajmohan, C., Pradep, K. and Karthikeyan, S. 2005. Influence of silymarin administration on hepatic glutathione-conjugating enzyme system in rats treated with antitubercular drugs. Drugs R D. 6, 395-400.

Wang, J., Shu, L., Yang, L., Zhang, M. and He, P. 2011. 2Hydroxy-3- methylanthraquinone from Hedyotis diffusa WILLD Induces Apoptosis via alteration of Fas/FasL and activation of caspase- 8 in human leukemic THP-1 Cells. Arch. Med. Res. 42, 577-583.
Warrier, P.K., Nambiar, V.P.K. and Ramankutty, C. 1995. Indian Medicinal Plants - A Compendium of 500 Species, vol. 3. Orient Longman Ltd., Chennai. pp. 120-123.

Zhang, L. and Li, X.F. 1992. Study on the mechanism of oleanolic acid against experimental liver injury in rats. Traditional Med. Clinical Pharmacol. 8, 24-26.

Zimhony, D., Cox, J.S., Welch, J.T., Wilcheze, C. and Jacobs, W.R. 2000. Pyrazinamide inhibits the eucaryotic-like fatty acid synthetase I (FASI) of mycobacterium tuberculosis. Nature Med. 6, 10431047. 